in a variety of biomarkers implicated in RA pathogenesis including inflammation (IL-1 $\beta, \mathrm{IL}-6, \mathrm{TNF} \alpha$ and SAA), matrix degradation and cartilage destruction (MMP1 and MMP3), immune cell trafficking (CXCL10, ICAM-1 and VCAM-1) and angiogenesis (VEGF). Cytokines involved in $T_{H} 1$ (IFN- $\left.\gamma, \mathrm{IL}-2, \mathrm{IL}-12\right)$ and $\mathrm{T}_{H} 17$ (IL-1 $\beta$, IL-6, IL-21, IL-23) cell subset differentiation and activity were significantly decreased. Additionally, decrease in the B-cell chemoattractant CXCL13 and the myeloid growth factor GM-CSF supports the anti-inflammatory effects of filgotinib treatment.

Table 1. Median percent change of biomarkers at week 12 from baseline for PBO and 200mg QD dose

\begin{tabular}{|c|c|c|c|c|c|c|c|c|}
\hline & $\begin{array}{c}\text { PBO } \\
(\mathrm{N}=78)\end{array}$ & $\begin{array}{l}\text { Filgotinib } \\
200 \mathrm{mg} Q \mathrm{QD} \\
(\mathrm{N}=75)\end{array}$ & & $\begin{array}{c}\mathrm{PBO} \\
(\mathrm{N}=78)\end{array}$ & $\begin{array}{l}\text { Filgotinib } \\
200 \mathrm{mg} Q \mathrm{QD} \\
(\mathrm{N}=75)\end{array}$ & & $\begin{array}{c}\mathrm{PBO}(\mathrm{N}=78) \\
(\mathrm{N}=78)\end{array}$ & $\begin{array}{c}\text { Filgotinib } \\
200 \mathrm{mg} \text { QD } \\
(\mathrm{N}=75)\end{array}$ \\
\hline BAFF & -2 & $-6^{\mathrm{NS}}$ & $\mathrm{IL}-2$ & -7 & $-20^{\star *}$ & MIP- $1 \beta$ & 0 & $-7^{\star}$ \\
\hline CRP & -8 & $-78^{\star \star \star}$ & IL-21 & 0 & $-28^{* *}$ & MMP-1 & -6 & $-26^{\star \star \star}$ \\
\hline CXCL-13 & 3 & $-40^{\star \star \star}$ & IL-23 & -6 & $-25^{\star \star \star}$ & MMP-3 & -9 & $-43^{\star \star \star}$ \\
\hline EGF & 0 & $0^{\mathrm{NS}}$ & $\mathrm{IL}-4$ & 0 & $0^{\mathrm{NS}}$ & RESISTIN & -1 & $-16^{\star \star \star}$ \\
\hline GM-CSF & 0 & $-26^{\star \star \star}$ & $\mathrm{IL}-5$ & 2 & $-14^{\star \star}$ & SAA & 7 & $-67^{\star \star \star}$ \\
\hline ICAM-1 & 0 & $-14^{\star \star \star}$ & $\mathrm{IL}-6$ & -20 & $-63^{\star \star \star}$ & sgp130 & 0 & $4^{\mathrm{NS}}$ \\
\hline IFN- $\gamma$ & -2 & $-21^{*}$ & $\mathrm{IL}-7$ & 1 & $-17^{\star \star \star}$ & TNF- $\alpha$ & 1 & $-15^{\star \star \star}$ \\
\hline IL-10 & -3 & $-17^{\star \star}$ & $\mathrm{IL}-8$ & -2 & $-12^{\mathrm{NS}}$ & TNF-RI & 0 & $-15^{\star \star \star}$ \\
\hline IL-12 & 0 & $-24^{\star \star \star}$ & IP-10 & -2 & $-31^{\star \star}$ & VCAM-1 & 0 & $-16^{\star \star \star}$ \\
\hline IL-13 & -1 & $-8^{\star \star}$ & LEPTIN & 6 & $23^{*}$ & VEGF & -2 & $-26^{\star \star \star}$ \\
\hline IL-17A & 2 & $-18^{*}$ & MCP-1 & 4 & $-8^{N S}$ & YKL-40 & -7 & $-33^{\star \star \star}$ \\
\hline IL-1 $\beta$ & -2 & $-26^{\star \star \star}$ & MIP-1 $\alpha$ & 1 & $-8^{\star *}$ & & & \\
\hline
\end{tabular}

p-values comparing $\%$ changes between filgotinib and PBO groups: NS, $p>0.05 ;{ }^{*} p<0.05$; ${ }^{\star *} \mathrm{p}<0.01 ;{ }^{* \star \star} \mathrm{p}<0.001$

Conclusions: Treatment with filgotinib decreased several factors that have key roles in RA for matrix degradation, cartilage destruction, angiogenesis, leukocyte adhesion and recruitment. The changes were accompanied by decreases in cytokines that promote and activate $T_{H} 1, T_{H} 17$, B-cells and myeloid cells that are important in RA. These findings provide insights into filgotinib mechanism of action and are consistent with its efficacy observed in RA patients.

Disclosure of Interest: P. Taylor Consultant for: Galapagos NV, Pfizer, Eli Lilly, UCB, GSK, R. Westhovens: None declared, A. Van der Aa Employee of: Galapagos NV, C. Jamoul Employee of: Galapagos NV, W. Li Employee of: Gilead Sciences, L. Goyal Employee of: Gilead Sciences, Y. Pan Employee of: Gilead Sciences, P. Harrison Employee of: Galapagos NV, C. Tasset Employee of: Galapagos NV, J. Tarrant Employee of: Gilead Sciences, R. Galien Employee of: Galapagos SASU

DOI: 10.1136/annrheumdis-2017-eular.5799

\section{THU0207 THE EFFECT OF THE USE OF GLUCOCORTICOIDS ON HEALTH ASSESSMENT QUESTIONNAIRE IN PATIENTS WITH RHEUMATOID ARTHRITIS IN CLINICAL REMISSION -DATA FROM KANSAI CONSORTIUM FOR WELL-BEING OF RHEUMATIC DISEASE PATIENTS (ANSWER COHORT)-}

R. Hara ${ }^{1}$, T. Fujimura ${ }^{1}$, M. Hashimoto ${ }^{2}$, M. Furu ${ }^{2}$, W. Yamamoto ${ }^{2}$, T. Hirano $^{3}$, K. Ebina ${ }^{4}$, S. Yoshida ${ }^{5}$, K. Nagai ${ }^{5}, \mathrm{H}$. Amuro ${ }^{6}, \mathrm{Y}$. Son ${ }^{6}$, T. Onishi ${ }^{7}$, K. Akashi ${ }^{7}$, M. Katayama ${ }^{8}$, T. Kira ${ }^{9}$, N. Shimmyo ${ }^{1}$, A. Kido ${ }^{1}$, Y. Akai ${ }^{1}$, T. Fujimoto ${ }^{1}$,

Y. Tanaka ${ }^{1} .{ }^{1}$ The Center for Rheumatic Diseases, Nara Medical University, Nara; ${ }^{2}$ Department of the Control for Rheumatic diseases, Graduate School of Medicine, Kyoto University, Kyoto; ${ }^{3}$ Department of Respiratory Medicine, Allergy and Rheumatic Disease, Graduate School of Medicine, Osaka University; ${ }^{4}$ Department of Orthopaedic Surgery, Osaka University, Graduate School of Medicine; ${ }^{5}$ Department of Internal Medicine (I), Osaka Medical College; ${ }^{6}$ First Department of Internal Medicine, Kansai Medical University, Osaka; ${ }^{7}$ Department of Rheumatology and Clinical Immunology, Kobe University Graduate School of Medicine, Kobe; ${ }^{8}$ Department of Rheumatology and Clinical Immunology, Osaka Red Cross Hospital, Osaka; ${ }^{9}$ Department of the Control for Rheumatic diseases, Nara Medical University, Nara, Japan

Background: In the treatment of patients with rheumatoid arthritis (RA), glucocorticoids (GCs) with csDMARDs remain an important treatment option given their capacity to increase clinical, structural and functional efficacy. On the other hand, it is reported that GCs usage even at low dosage significantly deteriorated functional capacity in patients with low disease activity state. In these previous study, disease activity and subsequent joint destruction have no small influence on functional disability.

Objectives: To investigate the effect of the use of glucocorticoids (GCs) in patients with RA who had maintained clinical remission on functional ability.

Methods: Among 2,649 patients with RA who achieved DAS-ESR $<2.6$ after 2013 in the multi-center cohort, 1,171 patients who had maintained DAS-ESR $<2.6$ were eligible. Clinical and demographic characteristics were collected at baseline. We calculated odds ratio (OR) (95\% confidence interval) of the use and dose of GCs to predict the yearly progression of HAQ-DI score adjusted for age, sex, BMI, disease duration, RF titer, ACPA titer, CRP, MMP-3, DAS28-ESR, HAQ-DI, use of MTX and use of biologic DMARDs as covariates in multiple logistic regression model.

Results: Characteristics of patients at baseline were as follows (median (IQR), proportion). The age was 61 (48-68) years, female was $70.6 \%$, disease duration was 4.5 (1.7-10.7) years, RF-positive was $64.4 \%$, ACPA-positive was $70 \%$,
DAS28-ESR was $2.0(1.6-2.6)$, HAQ-DI score was $0.125(0-0.5)$. Of the 1,171 patients, $235(20.1 \%)$ patients had been treated with oral GCs when achieving clinical remission. CRP $(0.06(0-0.2)$ vs $0.03(0-0.1), \mathrm{p}=0.03)$, MMP-3 (106.1 (73.2-172.8) vs 49.5 (36.5-77.2), $\mathrm{p}<0.001)$, SDAI $(2.9$ (1.5-5.9) vs 2.6 (1.04.8), $\mathrm{p}=0.003)$, DAS28-CRP (1.6 (1.3-2.0) vs $1.5(1.2-1.9), p=0.008)$, patients' global assessment (mm) (15 (5-31) vs 11 (3-25), $\mathrm{p}=0.006)$, physicians' global assessment $(\mathrm{mm})(6(3-12)$ vs $5(0-10), \mathrm{p}=0.001)$ and HAQ-DI $(0.38(0-0.88)$ vs $0.13(0-0.38), p<0.001)$ were significantly higher and disease duration was significantly longer (year) $(8.9(3.2-19.6)$ vs $4.1(1.6-9.3), p<0.01)$ in the GCs group compared to the non-GCs group. One hundred and fifty-eight $(67.2 \%)$ patients had been treated with GCs during follow up, and median dose was 4.5 (2.5-5.5) mg/day. Two hundred and eighty-seven (24.5\%) patients' yearly change of HAQ-DI score incresed. The adjusted OR of the use of GCs at baseline was 2.06 (1.21-3.51). The adjusted OR of the daily dose of GCs $<5 \mathrm{mg}$ was 1.61 $(0.73-3.56)$, whereas that of GCs $\geq 5 \mathrm{mg}$ was $2.65(1.11-6.34)$ in patients with keeping GCs use.

Conclusions: The use of GCs in RA patients with sustained remission was the risk factor of progression of HAQ-DI score dose-dependently.

Disclosure of Interest: None declared

DOI: 10.1136/annrheumdis-2017-eular.6924

\section{THU0208 METHOTREXATE POLYGLUTAMATES LEVELS IN ERYTHROCYTES WERE GENETICALLY AFFECTED IN RA PATIENTS WITH LOW DISEASE ACTIVITY FOR LONG PERIOD}

S. Kumagai $^{1,2}$, M. Nishida ${ }^{2}$, Y. Uemura ${ }^{1}$, M. Izumi $^{2}$, K. Abe $^{2}$, K. Yoneda ${ }^{2}$, Y. Noda $^{2}$, S. Sendo ${ }^{3}$, A. Ohishi ${ }^{3}$, M. Shinohara ${ }^{3}$, G. Tsuji ${ }^{2}$. ${ }^{1}$ Shinko Institute for Medical Research; ${ }^{2}$ Center for Rheumatic Dlseases, Shinko Hospital; ${ }^{3}$ Graduate School of Medicine, Kobe University, Kobe, Japan

Background: Detection of the intracellular levels of polyglutamated MTX (MTXPGn) can predict response of MTX or possibly its adverse effects. As efficacy and toxicity of MTX differs among individual patients, we had proposed a predictive model for MTX efficacy consisting of 9 SNPs (2015 EULAR). In the present study, we measured erythrocyte MTX-PGn in RA patients with low disease activity for long time receiving a stable dose of MTX, investigated their associations with genetic polymorphisms, and speculated MTX dose required to reach possible effective MTX-PG levels.

Objectives: To investigate if erythrocytes MTX-PGn concentration is associated with the 9 SNPs in 7 genes reportedly related to MTX-efficacy in RA patients with low disease activity.

Methods: The study was cross-sectional using 121 adult patients with RA in Shinko Hospital. All patients enrolled had received a stable dose of MTX (mean $8.9 \pm 0.3 \mathrm{mg} /$ week), and kept lower disease activity (DAS28-CRP $<2.7$, mean $1.9 \pm 0.4)$ for at least 3 months. Concentrations of MTX-PG with 1 - 5 glutamate residues (PG1- PG5) in erythrocytes were quantitated by LC-ESI-MS/MS as described by den Boer et al. Nine SNPs in 7 genes previously found to associate with efficacy of MTX by us were genotyped by RT-PCR (Applied Biosystems, Inc.). First, association of the 9 SNPs with concentrations on MTX-PGn was analyzed by one-way layout (Wilcoxon signed-rank test). Secondly, multivariate logistic regression analyses were performed to estimate roles of MTX dose and polymorphisms in concentrations of MTX-PGn.

Results: Total PGn concentrations were $82.1 \pm 31.7 \mathrm{nmol} / \mathrm{L}(\mathrm{m} \pm \mathrm{SD})$ and positively correlated with MTX dose (Rs $=0.4104, p<0.001$ ), but range of concentration was rather wide even if the dose was same. By one-way layout, GGH c.452C $>T$ was associated with PG1, PG2, and total PG, SLC19A1 c.80G $>A$ with total $P G$, and SLC28A3_c.267G $>A$ with PG3. Three SNPS (FPGS c. 192T $>C$, EPHX1 c.357G >A, SLC28A3 c.267G >A) were related to MTX doses. Next, we investigated roles of MTX dose and 9 SNPs in maintenance of MTX-PGn concentrations as by multiple regression analyses. As PG1 levels were related to GGH c. $452 \mathrm{C}>\mathrm{T}$ but not to MTX dose, PG1 levels were $38.2 \pm 19.6$ and $54.8 \pm 21.5$ $\mathrm{nmol} / \mathrm{L}$ in $\mathrm{CC}$ and CT genotypes, respectively $(\mathrm{P}=0.0291)$. MTX dose was strongly associated with PG3 levels as well as with those of PG4. MTX-PG3 levels were regressed as follows; MTX-PG3 $(\mathrm{nmol} / \mathrm{L})=-0.035+[2.04$ * MTX dose $]+[2.34$ * SLC19A1 c.80G >A] + [-2.01 * FPGS c. $192 \mathrm{~T}>\mathrm{C}]$. When upper and lower limits of them were defined, we can speculate MTX dose to reach the effective levels for individual patients. However, the ranges of effective levels were rather wide, suggesting that effectiveness of MTX may depend on not only concentrations of MTX-PG but also responsiveness to MTX-PG.

Conclusions: We measured erythrocyte MTX-PGn in RA patients with low disease activity and investigated for their associations with MTX dose and genetic polymorphisms. We could speculate MTX dose required to reach possible effective MTX-PG levels in individual patient.

\section{References:}

[1] Den Boer E, et al: Measuring methotrexate polyglutamates in red blood cells: A new LC-MS/MS-based method. Anal Bioanal Chem, 405:1673-1681, 2013. Disclosure of Interest: S. Kumagai Consultant for: Sysmex CO, M. Nishida: None declared, Y. Uemura: None declared, M. Izumi: None declared, K. Abe: None declared, K. Yoneda: None declared, Y. Noda: None declared, S. Sendo: None declared, A. Ohishi: None declared, M. Shinohara: None declared, G. Tsuji: None declared

DOI: 10.1136/annrheumdis-2017-eular.2585 